\title{
Assessing the Suitability of The Adapted Scientific Epistemic Beliefs Questionnaire in Namibia
}

\author{
Simson Ndadaleka Shaakumeni \\ Doctoral School of Education, University of Szeged \\ H-6722 Szeged, Petőfi sgt. 30-34., Hungary \\ E-mail: sshaakumeni@gmail.com
}

Received: Jan. 25, 2019

Accepted: April 29, 2019

Published: May 1, 2019

doi:10.5296/jse.v9i2.14704

URL: https://doi.org/10.5296/jse.v9i2.14704

\begin{abstract}
This study adapted and validated a questionnaire for assessing Namibian students' scientific epistemic beliefs and explore their relation to achievement in science, gender, grade and socioeconomic status. The study was correlational, with a sample of 944 (45\% male; 55\% female) Grades 11 and 12 students with the mean age $\mathrm{M}=17.9, \mathrm{SD}=1.4$. A Likert scale questionnaire comprised of four dimensions of beliefs: source; certainty; development; and justification of scientific knowledge. The adapted questionnaire had good reliability with the Cronbach's alpha of subscales ranging from .80 to .83 and the overall reliability of .70 . Model fit analysis yielded good statistical fit with Chi-square ratio to degrees of freedom= 2.71, $\mathrm{RMSEA}=0.043, \mathrm{CFI}=0.95, \mathrm{TLI}=0.94, \mathrm{SRMR}=.032$. The overall regression model was significant $F(4,939)=8.218, p<.001, R^{2}=.034$. Two dimensions, certainty $(\beta=.154$, $\mathrm{p}<.001)$ and justification $(\beta=.100, \mathrm{p}<.05)$ statistically significantly predicted achievement in science. There was statistically significant difference in beliefs about source in terms of gender and grade and about certainty in terms of grade. The results show that the questionnaire works well with the Namibian sample used given the good model fit for the data and reliability. Results are discussed in terms of $21^{\text {st }}$ century skills development.
\end{abstract}

Keywords: Scientific epistemic beliefs, Cross-cultural validation, Factor analysis, Namibia, $21^{\text {st }}$-century skills 


\section{MlMacrothink}

\section{Introduction}

The science curriculum in Namibia demands that students develop into scientific literate citizens (Ministry of Education, 2010). One of the components of scientific literacy is the understanding of the nature of scientific knowledge. However, the assessment of science knowledge in Namibian schools does not include this aspect of scientific literacy. All assessments mainly focus on subject content knowledge and omit the epistemic aspect of scientific inquiry needed to help students develop $21^{\text {st }}$ century skills. Epistemic beliefs refer to individual's beliefs about knowledge and knowing. Students need to develop sophisticated scientific epistemic beliefs in order to understand the nature of scientific knowledge and how such knowledge is constructed (Gu \& Belland, 2015). Since this aspect of scientific literacy is not assessed in schools, there is hardly any means through which to ascertain the extent to which the goals of the science curriculum are being met. One way to ascertain students' understanding of the nature of scientific knowledge and knowing is to assess their scientific epistemic beliefs. To achieve this, reliable and valid measures are required. Numerous epistemic beliefs measures have been developed and adapted in recent years (Buehl, Alexander, \& Murphy, 2002; Conley, Pintrich, Vekiri, \& Harrison, 2004; Murphy, Edwards, Buehl, \& Zeruth, 2007; Schraw, Bendixen, \& Dunkle, 2002; Tsai, Jessie Ho, Liang, \& Lin, 2011). However, a review of relevant literature suggests that these measures were either developed or adapted in the western world and Asia. None of such measures were tested in the cultural context of Namibia.

The aim of this study was to adapt and validate the scientific epistemic beliefs (SEB) questionnaire developed by Conley, Pintrich, Vekiri and Harrison (2004) using the Namibian senior secondary school (grade 11 and 12) students. The study attempted to answer three research questions:

1) How is the reliability of the adapted scientific epistemic beliefs questionnaire with the Namibian sample?

2) Does the data confirm the four-dimension hypothesised model?

3) Do students' scientific epistemic beliefs predict their achievement in science?

4) Is there a difference in mean levels of SEBs in terms of gender, grade and socioeconomic status?

\section{Background information}

\subsection{Terminology of epistemic beliefs}

Epistemology is an aspect of philosophy that is concerned with the nature of human knowledge and reasoning (Muis, Bendixen, \& Haerle, 2006). Educational researchers study epistemology in terms of individual's perspective. They focus on beliefs individuals possess about how knowing occurs, how knowledge is justified and how these affect individuals' cognitive processes ( $\mathrm{Gu} \&$ Belland, 2015). However, different terminologies referring to beliefs that people possess about nature of knowledge and knowing such as epistemic beliefs, epistemological beliefs, personal epistemology and epistemic cognition can be found in the 
literature. This suggests that there is no consensus regarding the terminology of this concept (Greene, Azevedo, \& Torney-Purta, 2008; Hofer, 2004).

According to Kitchener (2002), epistemic beliefs are beliefs about knowledge and knowing, including the source or justification of knowledge, whereas epistemological beliefs are beliefs about the field of epistemology or beliefs about the study of knowledge. Though personal epistemology or epistemological beliefs are used by most researchers in some measures of beliefs, it could be construed that such measures were aimed at the type of beliefs that Kitchener referred to as epistemic beliefs (Murphy et al., 2007). For this reason, the term epistemic beliefs is adopted for this study to refer to students' beliefs about scientific knowledge and knowing.

Greene et al. (2008) suggest that epistemic beliefs develop continuously from a naïve orientation to a more sophisticated position though in an unorganised way. Such beliefs begin with absolutism through multiplism and evaluativism. Absolutism is concerned with beliefs that knowledge is absolute and certain. Multiplism entails beliefs that knowledge is subjective and the evaluativist views knowledge as evolving, actively constructed and justified with evidence (Kienhues, Bromme, \& Stahl, 2008).

\subsection{Scientific epistemic beliefs}

On the sidelines of the general characterisations epistemic beliefs is a suggestion that domain-specific epistemic beliefs are more pertinent and influential in academic learning (Muis, Bendixen \& Haerle, 2006). For this reason, this study is located in the science domain.

Conley et al. (2004) proposed that scientific epistemic beliefs have four dimensions. The four dimensions are source (science knowledge comes from authority or experts); certainty (science knowledge has only one answer); development (science knowledge is evolving and changing); and justification (science knowledge should be based on evidence from different experiments and observations). Epistemic beliefs have been associated with learning and academic achievement in science (Cano, 2005; Stathopoulou \& Vosniadou, 2007; Trautwein $\&$ Lüdtke, 2007). These studies highlighted the importance of exploring student's views about the nature of scientific knowledge with a view to help them better understand science concepts. Studies that involved elementary students (e.g. Elder, 2002; Conley et al., 2004) provided conflicting results. Elder's study revealed that students perceived science knowledge as changing (development) and derived from experiments (justification). The other one by Conley and other colleagues found no significant changes in beliefs regarding the changing nature (development) and justification of scientific knowledge, though they found that higher achievement in science was associated with more sophisticated beliefs. Morever, similar studies done with upper secondary students showed more consistent results (Liang \& Tsai, 2010; Stathopoulou \& Vosniadou, 2007; Trautwein \& Lüdtke, 2007).

This is perhaps not surprising because earlier work on epistemological thinking (Kuhn, 1988) asserted that it was not easy to identify epistemological thinking among younger students. However, this assertion was contradicted by Wellman's (1992) work on children's theory of mind, suggesting that epistemological thinking begins at an early age and hence it should 
continue developing (Chandler, Hallett, \& Sokol, 2002). Against the foregoing, this study chose senior secondary students (Grades 11 and 12) as the most appropriate sample to validate the adapted questionnaire in the Namibian context.

\section{Adaptation of the SEB questionnaire}

The original questionnaire was developed for a particular culture and in the present study it has been adapted for a different culture. This necessitates a cross-cultural validation. Cross-cultural validation entails ascertaining whether instruments that were originally developed in a particular culture are meaningfully applicable and thus equivalent for use in another culture (Huang \& Wong, 2014). It has often been applied in psychological studies in which self-reporting measures are adapted for use in languages other than the original one. However, in the present study, both the original and the adapted version were in English. Cultural difference exists only in terms of geographical location: the original questionnaire was developed in the USA and the adapted version was used in Namibia (Africa).

Huang and Wong (2014) asserted that it might be challenging to adapt an instrument in a culturally relevant and comprehensible form while maintaining the meaning of the original items.

In the context of the present study, the adaptation entailed the removal of items that were deemed repetitive in an effort to shorten the questionnaire. Shortening the questionnaire was deemed beneficial as it could reduce redundancy suspected in the original questionnaire as well as mitigating respondents' fatigue. Wordy items were rephrased. Some words such as "stuff" were replaced with "things" for clarity. The development dimension showed lower reliability ( $\alpha=.66)$ compare to other three dimensions in the original SEB questionnaire. For this reason, the item "Ideas in science sometimes change" was replaced with one that reads "Scientific ideas may change because technology may lead to new findings".

The original version of the SEB questionnaire consisting of 26 items can be found in the Conley et al. (2004) article published in the Contemporary Educational Psychology Journal. The final adapted questionnaire had 22 items in total (Table 1).

Table 1. Comparison of items composition

\begin{tabular}{lcc}
\hline \multicolumn{1}{c}{ Dimensions of beliefs } & $\begin{array}{c}\text { Original SEB } \\
\text { (no. of items) }\end{array}$ & $\begin{array}{c}\text { Adapted SEB } \\
\text { (no. of items) }\end{array}$ \\
\hline Source & 5 & 4 \\
Certainty & 6 & 5 \\
Development & 6 & 6 \\
Justification & 9 & 7 \\
Total & 26 & 22 \\
\hline
\end{tabular}

Due to the adaptation of the questionnaire and the use of a sample different from the original one, it is recommended to examine the psychometric properties of the adapted instrument in order to assess its measurement precision and validity (Schraw, Bendixen, \& Dunkle, 2002). Previous studies that used the same questionnaire (Liang \& Tsai, 2010; Tsai, Jessie Ho, Liang 
\& Lin, 2011) confirmed its factorial structure suggesting that we could formulate an a priori hypothesis to test the questionnaire's factorial structure signifying that the four dimensions of beliefs proposed by Conley et al. (2004) should form distinct factors. Hence only confirmatory factor analyses were used to assess measurement model fit for the data in the present study.

\section{Methods}

\subsection{Participants and procedure}

After obtaining ethical approval from the university's institutional review board as well as permission from the gate keepers at the Ministry of Education in Namibia, consent forms were signed by participating students in conjunction with their parents or guardians. A sample of 944 ( $45 \%$ male; $55 \%$ female) grade 11 and 12 students with the mean age $M=17.9$, $\mathrm{SD}=1.4$ from three senior secondary schools in two regions (Omusati and Khomas) of Namibia participated in the study. Sampling was inherently convenient because the aim of the study was not to generalize findings but rather to obtain sufficient sample suitable for advanced statistical analysis to examine psychometric properties of the questionnaire.

All participating students were in senior secondary level (Grades 11 and 12). With assistance of the teachers, students responded to the items using the paper-and-pencil method. Students in the senior secondary level were preferred considering their anticipated proficiency in the English language compare to younger students. On average, students spent approximately 10 minutes to complete the questionnaire. Students were assigned numbers corresponding to their position in their class list. This enabled the researcher to link their SEB questionnaire responses to their mid-year science (Biology and Physical Science) marks obtained from school records. Science marks were used to relate students' SEBs to achievement in science. Provision was also made on the SEB questionnaire to collect some background data such as age, gender, grade and socioeconomic status (SES) by means of mother's level of education.

\subsection{Instruments}

The 22-item questionnaire was adapted from the scientific epistemic beliefs' questionnaire (Conley et al., 2004). Students were asked to indicate their level of agreement with the statements on beliefs about scientific knowledge. Items were unambiguously short, declarative statements without jargon. Each item was a five-point Likert scale of temporal frequency (Glynn, Taasoobshirazi, \& Brickman, 2009), wherein 1= strongly disagree; 2 = disagree; $3=$ not sure; $4=$ agree and $5=$ strongly agree. The questionnaire comprised of four dimensions of beliefs and example of items are given in brackets: source (Whatever the teacher says in science class is true); certainty (All questions in science have one right answer); development (Existing ideas in science may change as scientists come up with new ones); and justification (Good answers are based on evidence from many different experiments).

Each item had to be answered by means of circling the number corresponding to the option that best described their beliefs. All items were worded in both and negative directions however, items were negatively worded, all from the two naïve dimensions e.g. source and 
certainty were reverse scored so that a high score on a particular dimension indicates more sophisticated beliefs. The adapted questionnaire was given to one university lecturer of English and Linguistics who proof read and approved the language usage. Students' responses were captured manually and incomplete questionnaires were discarded, hence no missing data are found in the data set.

\subsection{Data analysis}

Ordinal data were analysed as if they were interval data (Glynn, Brickman, Armstrong, \& Taasoobshirazi, 2011). The reliability of the scales was assessed using Cronbach's alpha coefficient (Summers \& Abd-El-Khalick, 2017), using the statistical package for social sciences (SPSS) version 25. Construct validity was assessed using two criteria: convergent and discriminant (Cristobal, Flavián, \& Guinalíu, 2007).

Based on previous studies that used the same questionnaire (e.g. Liang \& Tsai, 2010; Tsai, Jessie Ho, Liang \& Lin, 2011), an assumption was made that the factorial structure confirmed by such studies through exploratory factor analysis should be sufficient for us to formulate an a priori hypothesis to test the adapted questionnaire's factorial structure suggesting that the four dimensions of beliefs proposed by Conley et al. (2004) should form distinct factors. Hence only confirmatory factor analyses in Mplus version 8 were used to assess measurement model fit using the ratio of chi-square to degrees of freedom $\left(\chi^{2} / d f\right)$, root-mean-square error of approximation (RMSEA), standardized root mean square residual (SRMR), Tucker-Lewis index (TLI) and comparative fit index (CFI) as fit indices (Glynn et al., 2011; Teo, 2013). Linear regression analysis was conducted to relate SEBs to achievement in science. Independent sample t-test was conducted to examine the difference in SEBs in terms of gender, grade and socioeconomic status. The reliability of the original SEB questionnaire ranged from .66 to .82 . It also showed reasonable model fit for the data with the RMSEA of 0.038 , the CFI was 0.90 , the non-normed fit index (NNFI) was 0.89 , and the root mean square residual (RMR) of 0.062 (Conley et al., 2004).

\section{Results and discussions}

\subsection{Reliability}

The reliability of the adapted SEB questionnaire was estimated using Cronbach's alpha coefficient. Reliability is a measure of internal consistency of respondents' responses across the items on a multiple-item measure. Essentially, all the items on such measures should reflect the same underlying construct thus respondents' scores on those items should be correlated with each other (Wieland, Durach, Kembro, \& Treiblmaier, 2017). Streiner (2003) suggested that the alpha coefficients of .70 and higher are ideal for research tools. 
Table 2. Reliability comparisons of original and adapted SEB questionnaires ( $N=944)$

\begin{tabular}{lcccc}
\hline Dimensions & \multicolumn{2}{c}{ No. of items } & \multicolumn{2}{c}{ Alpha $(\alpha)$} \\
\hline & Original & Adapted & Original & Adapted \\
Source & 5 & 4 & .82 & .80 \\
Certainty & 6 & 5 & .79 & .81 \\
Development & 6 & 6 & .66 & .83 \\
Justification & 9 & 7 & .76 & .80 \\
Overall reliability $(\alpha)$ & 26 & 22 & - & .70 \\
\hline
\end{tabular}

The reliabilities of the scores from the five factors in the questionnaire for this study were assessed using Cronbach's alpha coefficient. The reliability of scores from individual dimensions ranged from .80 to .83 (Table 2). The overall reliability of the scores on the adapted SEB questionnaire was .70. This suggests that the questionnaire had good overall reliability for the sample used although as all dimensions showed reliability values well above the recommended minimum threshold of .70 (Streiner, 2003). The overall reliability of the original SEB questionnaire was not reported, however, based on what was reported dimensions wise, the adapted SEB showed better reliability. It should be noted that the original SEB questionnaire was administered to elementary school students while the adapted one in the present study was administered to senior secondary students. The mode of administration was also different. In the original questionnaire, items were orally read out to students while in the present study, students responded by reading the questionnaires themselves.

Conley et al. (2004) reported that there was considerable redundancy in the original SEB questionnaire due to very high correlation between the source and certainty dimensions ( $\mathrm{r}$ $=.92$ ) which made it difficult to differentiate between the two concepts logically. However, our correlation analysis of the four dimensions (Table 3) showed that they were distinctly different from each other thus eliminated any possible redundancy of items.

Table 3. Correlation of adapted SEB dimensions $(\mathrm{N}=944)$

\begin{tabular}{lllllll}
\hline & M & SD & 1 & 2 & 3 & 4 \\
\hline 1. Source & 3.4 & .10 & - & & & \\
2. Certainty & 3.9 & .79 & -.041 & - & & \\
3. Development & 4.1 & .62 & .025 & .014 & - & \\
4. Justification & 4.3 & .56 & .015 & -.014 & .007 & - \\
\hline
\end{tabular}

$\mathrm{M}=$ mean $\quad \mathrm{SD}=$ Standard deviation

The overall level of beliefs was fairly low for the two naïve dimensions namely source $(\mathrm{M}=$ $3.4, \mathrm{SD}=.10$ and certainty $(\mathrm{M}=3.9, \mathrm{SD}=.79)$ but were higher for the sophisticated dimensions namely development $(\mathrm{M}=4.1, \mathrm{SD}=.62)$ and justification $(\mathrm{M}=4.3, \mathrm{SD}=.56)$.

Though these results are similar to the findings in the original questionnaire, it is difficult to interpret students' beliefs accurately due to the cross-sectional nature of the present study. Source and certainty were reverse scored so that high scores on them indicates sophisticated 


\section{Al Macrothink}

beliefs. Another assessment after an intervention could perhaps clarify this as one would be able to ascertain whether there were any changes in their beliefs. It should be noted that as such was not the aim of the present study. It is rather an opportunity for future research.

\subsection{Confirmatory factor analysis of the SEBs dimensions}

Confirmatory factor analysis was performed to verify the construct validity of the SEBs hypothesized four-dimension model. The values of item loadings, composite reliability (CR) and average variance extracted (AVE) are advised to evaluate convergent validity of the constructs (Hair, Black, Babin, Anderson \& Tatham, 2006). Convergent validity measures the level of correlation of multiple variables of the same construct that are in agreement (Ab Hamid, Sami, \& Sidek, 2017). As shown in Table 4, almost all loading values of the items were significant and higher than 0.5 (except for one item under justification which had a loading value of 0.35 ), indicating that in most cases more than $50 \%$ of the variance is explained by the dimensions. The CR values all exceeded the recommended cutoff value of .70 (Fornell \& Larcker, 1981). The AVE values for three of the dimensions (source, certainty, and development) met the minimum cutoff point of .50 while the AVE value for the justification dimension was .40. The AVE values for the four dimensions ranged from .40 to .50 . The $\mathrm{CR}$ values ranged from .80 to .83 (Table 4). Although one dimension had the AVE value below the preferred minimum cut-off point of .50 , convergent validity may still be adequate because the other three dimensions had AVE values of .50 and all dimensions had CR values above .70 (Fornell \& Larcker, 1981). Malhotra and Dash (2011) argued that the AVE is often too strict and validity can be established through $\mathrm{CR}$ alone.

Regarding goodness of fit of the measurement model, the ratio of chi-square to degrees of freedom $\left(\chi^{2} / d f\right)$ was 2.71, RMSEA $=0.043, \mathrm{CFI}=0.95, \mathrm{TLI}=0.94, \mathrm{SRMR}=0.032$, indicating that the measurement model fits the data very well. (Garson, 2015) The recommended resultant value for $\chi^{2} / d f$ should be in a recommended range of 1.0-3.0 (Glynn et al., 2011, Garson, 2015). The RMSEA and the SRMR are independent of the sample size but are sensitive to model misspecification and adequate fit values should be 0.06 and 0.08 or less respectively (Teo, 2013). The TLI and CFI are incremental indices with a recommended cutoff value of 0.95 , indicating goodness of fit, however, values above 0.90 are acceptable (Hooper, Coughlan, \& Mullen, 2008). Maximum likelihood (ML) estimation was used to estimate the model's parameters and fit indices. 


\section{Macrothink}

Table 4. Confirmatory factor analysis of the SEB four dimensions model $(\mathrm{N}=944)$

\begin{tabular}{cccc}
\hline Source $(\mathrm{S})$ & Factor loadings & CR & AVE \\
\hline S1 & $0.675^{* *}$ & & \\
S2 & $0.816^{* *}$ & 0.80 & 0.50 \\
S3 & $0.625^{* *}$ & & \\
S4 & $0.709^{* *}$ & & \\
Certainty (C) & & & \\
C5 & $0.653^{* *}$ & 0.82 & \\
C6 & $0.820^{* *}$ & & \\
C7 & $0.559^{* *}$ & & \\
C8 & $0.772^{* *}$ & & \\
C9 & $0.606^{* *}$ & & \\
Development (D) & & & \\
D10 & $0.744^{* *}$ & & \\
D11 & $0.506^{* *}$ & 0.83 & \\
D12 & $0.714^{* *}$ & & \\
D13 & $0.583^{* *}$ & & \\
D14 & $0.722^{* *}$ & & \\
D15 & $0.733^{* *}$ & & \\
Justification (J) & & & \\
J16 & $0.633^{* *}$ & & \\
J17 & $0.632^{* *}$ & & \\
J18 & $0.718^{* *}$ & & \\
J19 & $0.672^{* *}$ & & \\
J20 & $0.547^{* *}$ & & \\
J21 & $0.753^{* *}$ & & \\
J22 & $0.354^{* *}$ & & \\
\hline
\end{tabular}

** significant t-value, $p<.001$

Discriminant validity was assessed by comparing the square root of the AVE with the correlation of latent factors (dimensions) in the model (Hair et al., 2016) and was tenable as shown in Table 5. The extent to which latent factors (dimensions) differ from each other empirically defines discriminant validity (Hair, Hult, Ringle, \& Sarstedt, 2016). This means that a latent factor should explain the variance of its own indicators better than the variance of other latent factors (Ab Hamid et al., 2017). The square root of the AVE should be greater than .50 (Fornell \& Larcker, 1981) and greater than inter-latent factor correlations within the model (Hair, Black, Babin, \& Anderson, 2010). All dimensions support the precedent requirements and together with convergent validity, construct validity is confirmed. 


\section{1) Macrothink}

Table 5. Correlation matrix for SEB

\begin{tabular}{lcccccc}
\hline & $\mathrm{M}$ & $\mathrm{SD}$ & 1 & 2 & 3 & 4 \\
\hline 1. Development & 4.1 & .62 & 0.67 & & & \\
2. Source & 3.4 & .10 & 0.03 & 0.71 & & \\
3. Certainty & 3.9 & .79 & 0.02 & -0.06 & 0.69 & \\
4. Justification & 4.3 & .56 & 0.00 & 0.00 & -0.04 & 0.63 \\
\hline
\end{tabular}

Note: The diagonal numbers in italic are the square root of the AVE values

\subsection{Prediction of achievement in science}

Previous studies (Cano, 2005; Trautwein \& Lüdtke, 2007; Stathopoulou \& Vosniadou, 2007) have suggested that epistemic beliefs may have an influence on students' academic achievement. SEBs were used as predictors of achievement in science when regression analysis was conducted. Achievement in science was the outcome variable. Overall, the model fit proved to be good, $\chi^{2}(d f=4)=32.481$, TLI $=.954, \mathrm{CFI}=.957$, RMSEA $=.012$, SRMR $=.024$. The resulting standardized beta coefficients are shown in Fig. 1. The regression model was significant $F(4,939)=8.218, p<.001, R^{2}=.034$. However, only two dimensions namely certainty $(\beta=.154, \mathrm{p}<.001)$ and justification $(\beta=.100, \mathrm{p}<.05)$ statistically significantly predicted achievement in science. Source $(\beta=-.005, p=.886)$ and development $(\beta=-.021, \mathrm{p}=.503)$ negatively predicted achievement in science but the regression weights were not statistically significant.

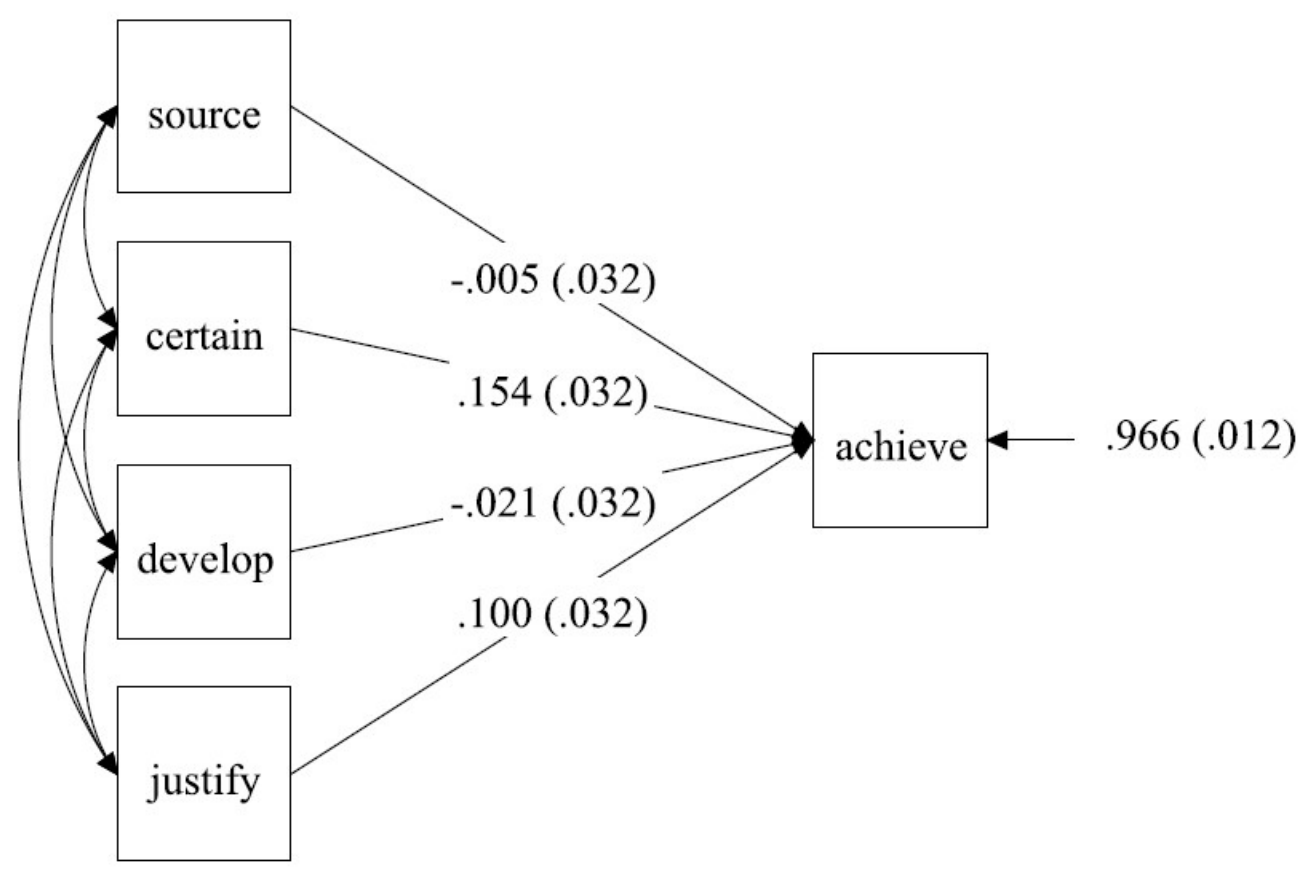

Figure 1. Linear regression of SEBs and achievement in science

With regard to certainty dimension, the findings in this study are contrary to what Trautwein and Lüdtke (2007) reported in their study involving upper secondary students. They found that certainty beliefs were significantly negative predictor of achievement. However, their 
achievement factor was broader than the present study which focused on science only.

\subsection{Differences in SEBs in terms of gender, grade and socioeconomic status}

In response to the fourth research question which asked whether there were differences in mean levels of SEBs in terms of gender, grade and socioeconomic status (SES), independent sample t-test was conducted for each dimension, separately for each group. The SES was determined by grouping students into two. One group for those whose mothers had a degree or diploma considered as 'high SES' and the other group was for those whose mothers had matric or below matric considered as 'low SES'. Those who didn't know about the level of their mothers' education were excluded from these analyses. The study found that there was statistically significant difference in beliefs about source of scientific knowledge in terms of gender (Table 6). Female students $(\mathrm{M}=3.44, \mathrm{SD}=.892)$ showed slightly more sophisticated beliefs about source of scientific knowledge than male students $(\mathrm{M}=3.26, \mathrm{SD}=.890), \mathrm{t}(942)$ $=-3.086, p<.05$, however, the effect size was very small, Cohen's $\mathrm{d}=0.16$, probably owing to the large sample size. Nonetheless, this was a positive finding considering that this is a validation study. The results were congruent with Cano (2005), although using different instruments, it was found that girls' epistemological beliefs about knowledge and learning, at all school levels, were more realistic than for the boys. There was no statistically significant difference in beliefs about other three dimensions in terms of gender. This is in line with Pintrich (2002) who asserted that there were no important differences in epistemological thinking in terms of gender. The original study (Conley et al., 2004) also reported that boys and girls in the fifth grade appeared to have similar scientific epistemic thinking as they didn't find evidence suggesting the effects of gender nor any moderating effects of gender over time.

Table 6. Mean difference in terms of gender

\begin{tabular}{|c|c|c|c|c|c|c|c|c|c|c|c|}
\hline \multirow[b]{2}{*}{ SEBs } & \multirow[b]{2}{*}{ Gender } & \multirow[b]{2}{*}{$\mathrm{N}$} & \multirow[b]{2}{*}{ M } & \multirow[b]{2}{*}{ SD } & \multirow[b]{2}{*}{$\mathrm{t}$} & \multirow[b]{2}{*}{$\mathrm{df}$} & \multirow{2}{*}{$\begin{array}{c}\text { Sig. } \\
\text { (2-tailed) }\end{array}$} & \multirow{2}{*}{$\begin{array}{c}\text { Mean } \\
\text { Difference }\end{array}$} & \multirow{2}{*}{$\begin{array}{l}\text { Std. Error } \\
\text { Difference }\end{array}$} & \multicolumn{2}{|c|}{$\begin{array}{c}95 \% \mathrm{CI} \text { of the } \\
\text { Difference }\end{array}$} \\
\hline & & & & & & & & & & Lower & Upper \\
\hline \multirow[t]{2}{*}{ Source } & Male & 421 & 3.26 & .890 & -3.086 & 942 & .002 & -.180 & .058 & -.295 & -.066 \\
\hline & Female & 523 & 3.44 & .892 & & & & & & & \\
\hline \multirow[t]{2}{*}{ Certainty } & Male & 421 & 3.92 & .804 & .301 & 942 & .763 & .016 & .052 & -.086 & .117 \\
\hline & Female & 523 & 3.90 & .773 & & & & & & & \\
\hline \multirow[t]{2}{*}{ Development } & Male & 421 & 4.13 & .619 & -.218 & 942 & .827 & -.009 & .040 & -.088 & .070 \\
\hline & Female & 523 & 4.14 & .613 & & & & & & & \\
\hline \multirow[t]{2}{*}{ Justification } & Male & 421 & 4.24 & .571 & -.851 & 942 & .395 & -.031 & .037 & -.104 & .041 \\
\hline & Female & 523 & 4.27 & .555 & & & & & & & \\
\hline
\end{tabular}

With regard to grades, there was a statistically significant difference in beliefs about source and certainty between grades (Table 7). Grade 11 students $(\mathrm{M}=3.43, \mathrm{SD}=.879)$ showed more sophisticated beliefs about source than Grade 12 students $(\mathrm{M}=3.29, \mathrm{SD}=.908), \mathrm{t}(942)=$ 2.389, $p<.05$, with Cohen's $\mathrm{d}=0.22$, suggesting a small but significant difference. Alternately, Grade 12 students $(\mathrm{M}=4.00, \mathrm{SD}=763)$ showed more sophisticated beliefs about certainty than Grade 11 students $(\mathrm{M}=3.83, \mathrm{SD}=.800), \mathrm{t}(940.69)=-3.423, \mathrm{p}<.05$, which is 
also a small but significant difference (Cohen's d=0.20). These results are in conflict with the hypothesis that Grade 12 students would have more sophisticated beliefs than Grade 11 students, because they have been studying science longer. However, this can only be adequately tested with a pre-test post-test kind of assessment. As such was not possible for the present study. Although in the original study (Conley et al., 2004) students were assessed at two points in time, mimicking a pre-test post-test scenario, it did not compare different grades as it used fifth graders only.

Table 7. Mean difference in terms of grade

\begin{tabular}{|c|c|c|c|c|c|c|c|c|c|c|c|}
\hline \multirow[b]{2}{*}{ SEBs } & \multirow[b]{2}{*}{ Grade } & \multirow[b]{2}{*}{$\mathrm{N}$} & \multirow[b]{2}{*}{ M } & \multirow[b]{2}{*}{ SD } & \multirow[b]{2}{*}{$\mathrm{t}$} & \multirow[b]{2}{*}{ df } & \multirow{2}{*}{$\begin{array}{c}\text { Sig. } \\
\text { (2-taile } \\
\text { d) }\end{array}$} & \multirow{2}{*}{$\begin{array}{c}\text { Mean } \\
\text { Difference }\end{array}$} & \multirow{2}{*}{$\begin{array}{l}\text { Std. Error } \\
\text { Difference }\end{array}$} & \multicolumn{2}{|c|}{$\begin{array}{c}95 \% \mathrm{CI} \text { of the } \\
\text { Difference }\end{array}$} \\
\hline & & & & & & & & & & Lower & Upper \\
\hline \multirow[t]{2}{*}{ Source } & 11 & 492 & 3.43 & .879 & 2.389 & 942 & .017 & .139 & .058 & .025 & .253 \\
\hline & 12 & 452 & 3.29 & .908 & & & & & & & \\
\hline \multirow[t]{2}{*}{ Certainty } & 11 & 492 & 3.83 & .800 & -3.423 & 940.69 & .001 & -.174 & .051 & -.274 & -.074 \\
\hline & 12 & 452 & 4.00 & .763 & & & & & & & \\
\hline \multirow[t]{2}{*}{ Development } & 11 & 492 & 4.14 & .586 & .075 & 942 & .940 & .003 & .040 & -.076 & .082 \\
\hline & 12 & 452 & 4.14 & .647 & & & & & & & \\
\hline \multirow[t]{2}{*}{ Justification } & 11 & 492 & 4.25 & .554 & -.696 & 942 & .487 & -.025 & .037 & -.097 & .046 \\
\hline & 12 & 452 & 4.27 & .571 & & & & & & & \\
\hline
\end{tabular}

The results showed that there was no statistically significant difference in the means of high and low SES across all four dimensions of beliefs. Both groups showed overall lower scores on source and certainty and higher scores on development and justification (Table 8). The results suggest that regardless of the SES, students possessed less sophisticated beliefs about source (high SES: $\mathrm{M}=3.30, \mathrm{SD}=.904$; low $\mathrm{SES}: \mathrm{M}=3.41, \mathrm{SD}=.824$ ) and certainty (high SES: $\mathrm{M}=3.90, \mathrm{SD}=.827$; low $\mathrm{SES}: \mathrm{M}=3.92, \mathrm{SD}=.771$ ) but possessed more sophisticated beliefs about development (high $\mathrm{SES}: \mathrm{M}=4.16, \mathrm{SD}=.561$; low $\mathrm{SES}: \mathrm{M}=4.06, \mathrm{SD}=.693$ ) and justification (high $\mathrm{SES}: \mathrm{M}=4.24, \mathrm{SD}=.653$; low $\mathrm{SES}: \mathrm{M}=4.30, \mathrm{SD}=.513$ ).

Table 8. Mean difference in terms of socioeconomic status

\begin{tabular}{|c|c|c|c|c|c|c|c|c|c|c|c|}
\hline \multirow[b]{2}{*}{ SEBs } & \multirow[b]{2}{*}{ SES } & \multirow[b]{2}{*}{$\mathrm{N}$} & \multirow[b]{2}{*}{ M } & \multirow[b]{2}{*}{ SD } & \multirow[b]{2}{*}{$\mathrm{t}$} & \multirow[b]{2}{*}{$\mathrm{df}$} & \multirow{2}{*}{$\begin{array}{c}\text { Sig. } \\
\text { (2-tailed } \\
\text { ) }\end{array}$} & \multirow{2}{*}{$\begin{array}{c}\text { Mean } \\
\text { Difference }\end{array}$} & \multirow{2}{*}{$\begin{array}{l}\text { Std. Error } \\
\text { Difference }\end{array}$} & \multicolumn{2}{|c|}{$\begin{array}{c}95 \% \text { CI of the } \\
\text { Difference }\end{array}$} \\
\hline & & & & & & & & & & Lower & Upper \\
\hline \multirow[t]{2}{*}{ Source } & High SES & 215 & 3.30 & .904 & -1.427 & 503 & .154 & -.110 & .077 & -.262 & .042 \\
\hline & Low SES & 290 & 3.41 & .824 & & & & & & & \\
\hline \multirow[t]{2}{*}{ Certainty } & High SES & 215 & 3.90 & .827 & -.237 & 503 & .813 & -.017 & .072 & -.158 & .124 \\
\hline & Low SES & 290 & 3.92 & .771 & & & & & & & \\
\hline \multirow[t]{2}{*}{ Development } & High SES & 215 & 4.16 & .561 & 1.787 & 503 & .075 & .103 & .058 & -.010 & .216 \\
\hline & Low SES & 290 & 4.06 & .693 & & & & & & & \\
\hline \multirow[t]{2}{*}{ Justification } & High SES & 215 & 4.24 & .653 & -1.228 & 393.544 & .220 & -.066 & .054 & -.172 & .040 \\
\hline & Low SES & 290 & 4.30 & .513 & & & & & & & \\
\hline
\end{tabular}

This implies that students' mothers' level of education did not have an influence on their 
beliefs about scientific knowledge and knowing. These findings are contrary to what was reported about SES in the original study (Conley et al., 2004). It was reported that low SES students scored lower in all four dimensions of beliefs than average SES students. Suggesting that low SES students appeared to possess less sophisticated epistemic beliefs. It should be noted that the criteria for classifying students into low and high SES were different. In the original study, the SES was determined in terms of eligibility for free lunch at school while in the present study it was based on mothers' level of education.

\section{Conclusion}

This study set out to adapt and validate the scientific epistemic beliefs questionnaire using the Namibian sample of Grades 11 and 12 students. The overall level of beliefs was fairly low for the two naïve dimensions namely source and certainty but was higher for the sophisticated dimensions namely development and justification. These results were similar to the findings of the original questionnaire but it is difficult to interpret students' beliefs accurately due to the cross-sectional nature of the present study. Source and certainty were reverse scored because their items were reverse-coded, so that high scores on them indicate more sophisticated beliefs. Although reverse-coded items may help mitigate response bias, it can also lead to confusion among respondents. Respondents, especially second language speakers, who are not careful may miss the reversing or the negative form and may incorrectly respond to the reverse-coded items (Weijters, Baumgartner, \& Schillewaert, 2013).

Another assessment after an intervention could perhaps clarify the current state of students' beliefs as one would be able to ascertain whether there were any changes in beliefs. It should be noted that as such was not the aim of the present study. It is rather an opportunity for future research.

The results indicate that the adapted questionnaire had adequate construct validity owing to good convergent and discriminant validity estimates. Similarly, the reliability of responses in terms of both alpha coefficient and composite reliability estimates were good as the estimates for all four dimensions of beliefs were above the preferred cut-off point of .70. The measurement model shows good fit for the data with good fit statistics such as $\chi^{2} / d f$, RMSEA, SRMR, TLI and CFI. In comparison with the original questionnaire, the present study showed better model fit indices. This study also found that two dimensions of beliefs namely certainty and justification statistically significantly predicted achievement in science in this sample.

Further analyses revealed that there was a statistically significant difference in beliefs about source in terms of gender and grade as well as about certainty in terms of grade. No difference was found in other two dimensions of beliefs (development and justification) in terms of gender, grade and socioeconomic status. The results showed that the adapted questionnaire works well with the Namibian sample used given the good model fit for the data and reliability. This study focused on the exit phase of the Namibian basic education (Grades 11 and 12). At the moment, there are no formal assessments for students' scientific epistemic beliefs within the Namibian education system. Elsewhere especially in the developed world, there has been a shift of learning goals in recent years, from content 
knowledge to emphasising the epistemic aspect of scientific inquiry needed to help students develop $21^{\text {st }}$ century skills (Gu \& Belland, 2015).

As such, Namibia as a developing nation needs to keep abreast with the developments in science education in order to achieve the aims of its science curriculum. The main aim of the science curriculum is to provide students with the basic scientific background and develop them into scientifically literate citizens who are capable of dealing with $21^{\text {st }}$ century challenges (Ministry of Education, 2010). Thus, developing sophisticated scientific epistemic beliefs is a prerequisite for developing $21^{\text {st }}$ century skills. However, the fact that epistemic beliefs are not explicitly emphasised during science instructions and subsequently not assessed, also given the dearth of instruments for assessing scientific epistemic beliefs in the Namibian cultural context, this study intended to provide a valid instrument for use by researchers of science education. Copyrights for the original questionnaire is with the Contemporary Educational Psychology Journal.

\section{References}

Ab Hamid, M. R., Sami, W., \& Sidek, M. H. (2017). Discriminant Validity Assessment : Use of Fornell \& Larcker criterion versus HTMT Criterion. Journal of Physics: Conference Series, 890(12163). https://doi.org/https://doi.org/10.1088/1742-6596/890/1/012163

Buehl, M. M., Alexander, P. A., \& Murphy, P. K. (2002). Beliefs about schooled knowledge: Domain specific or domain general? Contemporary Educational Psychology, 27(3), 415-449. https://doi.org/10.1006/ceps.2001.1103

Cano, F. (2005). Epistemological beliefs and approaches to learning: Their change through secondary school and their influence on academic performance. British Journal of Educational Psychology, 75(2), 203-221. https://doi.org/10.1348/000709904X22683

Chandler, M. J., Hallett, D., \& Sokol, B. W. (2002). Competing claims about competing knowledge claims. In P. R. Pintrich (Ed.), Personal epistemology: The psychology of beliefs about knowledge and knowing (pp. 145-168). Mahwah, NJ, USA: Lawrence Erlbaum Associates.

Conley, A. M. M., Pintrich, P. R., Vekiri, I., \& Harrison, D. (2004). Changes in epistemological beliefs in elementary science students. Contemporary Educational Psychology, 29(2), 186-204. https://doi.org/10.1016/j.cedpsych.2004.01.004

Cristobal, E., Flavián, C., \& Guinalíu, M. (2007). Perceived e-service quality (PeSQ). Managing Service Quality: An International Journal, 17(3), 317-340. https://doi.org/10.1108/09604520710744326

Decoster, J., \& Hall, G. P. (2005). Scale Construction Notes. Construction, 9(2), 177-204. https://doi.org/10.1300/J027v09n02_12

Elder, A. D. (2002). Characterizing fifth grade students_epistemological beliefs in science. In P. R. Pintrich(Ed.), Personal epistemology: The psychology of beliefs about knowledge and knowing (pp. 347-364). Mahwah, NJ, USA: Lawrence Erlbaum Associates. 
Fornell, C., \& Larcker, D. F. (1981). Evaluating Structural Equation Models with Unobservable Variables and Measurement Error. Journal of Marketing Research, 18(1), 39. https://doi.org/10.2307/3151312

Garson, G. D. (2015). Structural equation modelling. Asheboro, NC: Statistical Associates Publishers.

Glynn, S. M., Brickman, P., Armstrong, N., \& Taasoobshirazi, G. (2011). Science motivation questionnaire II: Validation with science majors and nonscience majors. Journal of Research in Science Teaching, 48(10), 1159-1176. https://doi.org/10.1002/tea.20442

Glynn, S. M., Taasoobshirazi, G., \& Brickman, P. (2009). Science motivation questionnaire: Construct validation with nonscience majors. Journal of Research in Science Teaching, 46(2), 127-146. https://doi.org/10.1002/tea.20267

Greene, J. A., Azevedo, R., \& Torney-Purta, J. (2008). Modeling epistemic and ontological cognition: Philosophical perspectives and methodological directions. Educational Psychologist, 43(3), 142-160. https://doi.org/10.1080/00461520802178458

Gu, J., \& Belland, B. R. (2015). Emerging Technologies for STEAM Education. Emerging Technologies for STEAM Education, 39-60. https://doi.org/10.1007/978-3-319-02573-5

Hair, J., Black, W., Babin, B., \& Anderson, R. (2010). Multivariate data analysis (7th ed.). Upper Saddle River, NJ, USA: Prentice-Hall, Inc.

Hair Jr, J. F., Hult, G. T. M., Ringle, C., \& Sarstedt, M. (2016). A primer on partial least squares structural equation modeling (PLS-SEM). Sage Publications.

Hair, J. F., Black, W. C., Babin, B. J., Anderson, R. E., \& Tatham, R. L. (2006). Multivariate data analysis (6th ed.). Upper Saddle River, NJ: Pearson Education.

Hofer, B. K. (2004). Epistemological Understanding as a Metacognitive Process: Thinking Aloud During Online Searching. Educational Psychologist, 39(1), 43-55. https://doi.org/10.1207/s15326985ep3901

Hooper, D., Coughlan, J., \& Mullen, M. R. (2008). Structural Equation Modelling: Guidelines for Determining Model Fit. The Electronic Journal of Business Research Methods, $6(1), 53-60$.

Huang, W.Y., \& Wong, S.H. (2014). Cross-cultural validation. In: A.C. Michalos (Eds), Encyclopedia of quality of life and well-being research (pp. 1369-1371). Dordrecht: Springer.

Kienhues, D., Bromme, R., \& Stahl, E. (2008). Changing epistemological beliefs: The unexpected impact of a short-term intervention. British Journal of Educational Psychology, 78(4), 545-565. https://doi.org/10.1348/000709907X268589

Kitchener, R. F. (2002). Folk epistemology: An introduction. New Ideas in Psychology, 20(2-3), 89-105. https://doi.org/10.1016/s0732-118x(02)00003-x 
Kuhn, D. (1988). Cognitive development. In M. H. Bornstein (Ed.), Developmental psychology: An advanced textbook (pp. 205-260). Hillsdale, NJ: Lawrence Erlbaum Associates.

Liang, J. C., \& Tsai, C. C. (2010). Relational analysis of college science-major students' epistemological. International Journal of Science Education, 32(17), 2273-2289. https://doi.org/10.1080/09500690903397796

Malhotra, N. K., \& Dash, S. (2011). Marketing Research: An applied orientation. London: Pearson Publishing.

Muis, K. R., Bendixen, L. D., \& Haerle, F. C. (2006). Domain-generality and domain-specificity in personal epistemology research: Philosophical and empirical reflections in the development of a theoretical framework. Educational Psychology Review, 18(1), 3-54. https://doi.org/10.1007/s10648-006-9003-6

Murphy, P. K., Edwards, M. N., Buehl, M. M., \& Zeruth, J. A. (2007). Using the domain-specific beliefs questionnaire with adolescents enrolled in high-poverty, high-minority schools: Examining psychometric properties. Journal of Experimental Education, 76(1), 3-25. https://doi.org/10.3200/JEXE.76.1.3-25

Namibia. Ministry of Education [MoE]. (2010). The national curriculum for basic education. Okahandja: NIED

Schraw, G., Bendixen, L. D., \& Dunkle, M. E. (2002). Development and validation of the Epistemic Belief Inventory (EBI). In K. Hofer \& P. R. Pintrich (Eds.), Personal epistemology: The psychology of beliefs about knowledge and knowing (pp. 261-275). Mahwah, NJ, US: Lawrence Erlbaum Associates Publishers.

Pintrich, P. R. (2002). Future challenges and directions for theory and research on personal epistemology. In P. R. Pintrich (Ed.), Personal epistemology: The psychology of beliefs about knowledge and knowing (pp. 389-414). Mahwah, NJ, USA: Lawrence Erlbaum Associates.

Stathopoulou, C., \& Vosniadou, S. (2007). Exploring the relationship between physics-related epistemological beliefs and physics understanding. Contemporary Educational Psychology, 32(3), 255-281. https://doi.org/10.1016/j.cedpsych.2005.12.002

Streiner, D. L. (2003). Starting at the Beginning: An Introduction to Coefficient Alpha and Internal Consistency Starting at the Beginning: An Introduction to Coefficient Alpha and Internal Consistency. Journal of Personality Assessment, 80(1), 99-103. https://doi.org/10.1207/S15327752JPA8001

Summers, R., \& Abd-El-Khalick, F. (2017). Development and validation of an instrument to assess student attitudes toward science across grades 5 through 10. Journal of Research in Science Teaching, 55(2), 172-205. https://doi.org/10.1002/tea.21416

Teo, T. (2013). Examining the Psychometric Properties of the Epistemic Belief Inventory (EBI). Journal of Psychoeducational Assessment, 31(1), 72-79. https://doi.org/10.1177/ 0734282912449436 


\section{Macrothink}

Trautwein, U., \& Lüdtke, O. (2007). Epistemological beliefs, school achievement, and college major: A large-scale longitudinal study on the impact of certainty beliefs. Contemporary Educational Psychology, 32(3), 348-366. https://doi.org/10.1016/j.ce dpsych.2005.11.003

Tsai, C. C., Jessie Ho, H. N., Liang, J. C., \& Lin, H. M. (2011). Scientific epistemic beliefs, conceptions of learning science and self-efficacy of learning science among high school students. Learning and Instruction, 21(6), 757-769. https://doi.org/10.1016/j.lear ninstruc.2011.05.002

Weijters, B., Baumgartner, H., \& Schillewaert, N. (2013). Reversed item bias: An integrative model. Psychological Methods, 18(3), 320-334. https://doi.org/10.1037 /a0032121

Wellman, H. M. (1992). The child's theory of mind. Cambridge, MA: The MIT Press.

Wieland, A., Durach, C. F., Kembro, J., \& Treiblmaier, H. (2017). Statistical and judgmental criteria for scale purification. Supply Chain Management: An International Journal, 22(4), 321-328. https://doi.org/10.1108/SCM-07-2016-0230

\section{Appendix: Adapted Scientific Epistemic Beliefs Questionnaire}

1. Everybody has to believe what scientists say.

2. In science, you have to believe what the science books say about things.

3. Whatever the teacher says in science class is true.

4. If you read something in a science book, you can be sure it is true.

5. All questions in science have one right answer.

6. The most important part of doing science is coming up with the right answer.

7. Scientists know everything about science; there is not 1 2 3 4 5 much more to know.

$\begin{array}{lllll}1 & 2 & 3 & 4 & 5\end{array}$


8. Scientific knowledge is always true. $\quad \begin{array}{lllll} & 1 & 2 & 3 & 4\end{array}$

9. Once scientists have the result from an experiment, that $\quad \begin{array}{llllll}1 & 2 & 3 & 4\end{array}$ is the only answer.

10. Some ideas in science today are different than what

$\begin{array}{lllll}1 & 2 & 3 & 4 & 5\end{array}$
scientists used to think.

11. The ideas in science books sometimes change.

$\begin{array}{lllll}1 & 2 & 3 & 4 & 5\end{array}$

12. There are some questions that even scientists cannot

$\begin{array}{lllll}1 & 2 & 3 & 4 & 5\end{array}$
answer.

13. Sometimes scientists change their minds about what is $\begin{array}{lllll}1 & 2 & 3 & 4 & 5\end{array}$ true in science.

14. Existing ideas in science may change as scientists come up $\quad \begin{array}{lllll}1 & 2 & 3 & 4\end{array}$ with new ones.

15. Scientific ideas may change because technology may lead $\quad \begin{array}{lllll}1 & 2 & 3 & 4 & 5\end{array}$ to new findings.

16. Ideas about science experiments come from being curious $\quad \begin{array}{lllll}1 & 2 & 3 & 4 & 5\end{array}$ and thinking about how things work.

17. In science, there can be more than one way for scientists $\quad \begin{array}{lllll}1 & 2 & 3 & 4\end{array}$ to test their ideas.

18. One important part of science is doing experiments to

$\begin{array}{lllll}1 & 2 & 3 & 4 & 5\end{array}$
come up with new ideas about how things work.

19. Good answers are based on evidence from many different $\quad \begin{array}{lllll}1 & 2 & 3 & 4 & 5\end{array}$ experiments.

20. Ideas in science can come from your own questions and $\begin{array}{lllll}1 & 2 & 3 & 4 & 5\end{array}$ experiments.

21. It is good to try experiments more than once to make sure $\quad \begin{array}{lllll}1 & 2 & 3 & 4 & 5\end{array}$ of your results.

22. Good ideas in science can come from anybody, not just $\quad \begin{array}{llll}1 & 2 & 3 & 4\end{array}$ from scientists. 